\title{
Dual mobility total hip replacement in a high risk population
}

\author{
Jatinder Singh Luthra*, Amur Al Riyami, and Mohamad Kasim Allami \\ Khoula Hospital, PO Box 90, PC 116, Mina Al Fahal, Oman
}

Received 5 July 2016, Accepted 8 November 2016, Published online 7 December 2016

\begin{abstract}
Objective: The purpose of the study was to evaluate results of dual mobility total replacement in a high risk population who take hip into hyperflexed position while sitting and praying on the floor.

Method: The study included 65 (35 primary total replacement and 30 complex total hip replacement) cases of total hip replacement using avantage privilege dual mobility cup system from biomet. A cemented acetabular component and on femoral side a bimetric stem, either cemented or uncemented used depending on the canal type. Ten cases were examined fluoroscopically in follow up.

Result: There was dislocation in one patient undergoing complex hip replacement. Fluoroscopy study showed no impingement between the neck of prosthesis and acetabular shell at extremes of all movements.

Conclusion: The prevalence of dislocation is low in our high risk population and we consider it preferred concept for patients undergoing complex total hip replacement.
\end{abstract}

Key words: Dual mobility, Total hip replacement, Dislocation.

\section{Introduction}

Instability is an extremely significant cause of morbidity following total hip replacement (THR). The incidence of instability after primary and revision replacement has been reported to be as high as $7 \%$ and $25 \%$, respectively [1]. The cumulative risk of first time dislocation is $2 \%$ at one year and $7 \%$ after 15 years of primary hip replacement [2]. The concept of dual mobility articulation was developed in 1970 by Bousquet to increase the range of motion and to decrease dislocation risk. It combined a small head to decrease wear (low friction arthroplasty principles stated by Charnley [3]) and a large head to increase stability (MacKee and Farrar [4]). Several studies have looked at the outcome of dual mobility articulation in primary THR [5-18] and in revision THR [5, 19-24].

We present our series of cases performed in high risk population whose cultural demand requires sitting on the floor [25].

\section{Material and methods}

This is a retrospective study of 65 patients undergoing complex primary or revision hip replacement for different etiologies in selective cases. The cases included in our study

\footnotetext{
*Corresponding author: jatinder12345@gmail.com
}

were consecutive cases of dual mobility cup (DMC) done at our institute from June 2010 till July 2014.

The inclusion criteria for a patient undergoing total hip replacement (THR) to have DMC were those at high risk of dislocation. These included patients who were either more than 60 years, had poor soft tissue envelope around the hip, were non compliant, were elderly and had sustained femoral neck fracture, underwent failed hip surgeries, had a septic hip, and had undergone a revision THR irrespective of the cause (Figures 1 and 2).

Surgery was performed in lateral decubitus position using Moore's (Southern) approach to hip. The acetabular cup was from Biomet (Avantage privilege DMC) and a bimetric femoral stem was used. A calcar bearing stem was used in three cases and a long stem was used in 10 cases to bypass the defect, or stress riser. Three patients with a fracture of the trochanter were stabilized with a distal tibial locking plate. Structural allograft was used for the support of proximal femur in one patient. Palacos cement was used to fix the acetabular cup in 63 cases and 2 cases were uncemented.

Out of 65 cases, 35 were male and 30 female. The age of the patient ranged from 23 years to 91 years with a mean age of 61 years. It was primary hip replacement in 30 cases and revision surgery (complex THR) in 35 cases. The etiologies of primary and revision cases are shown in Tables 1 and 2, respectively. The cases of osteoarthritis, femoral neck fracture, and fracture acetabulum were those of the elderly. The sickler 

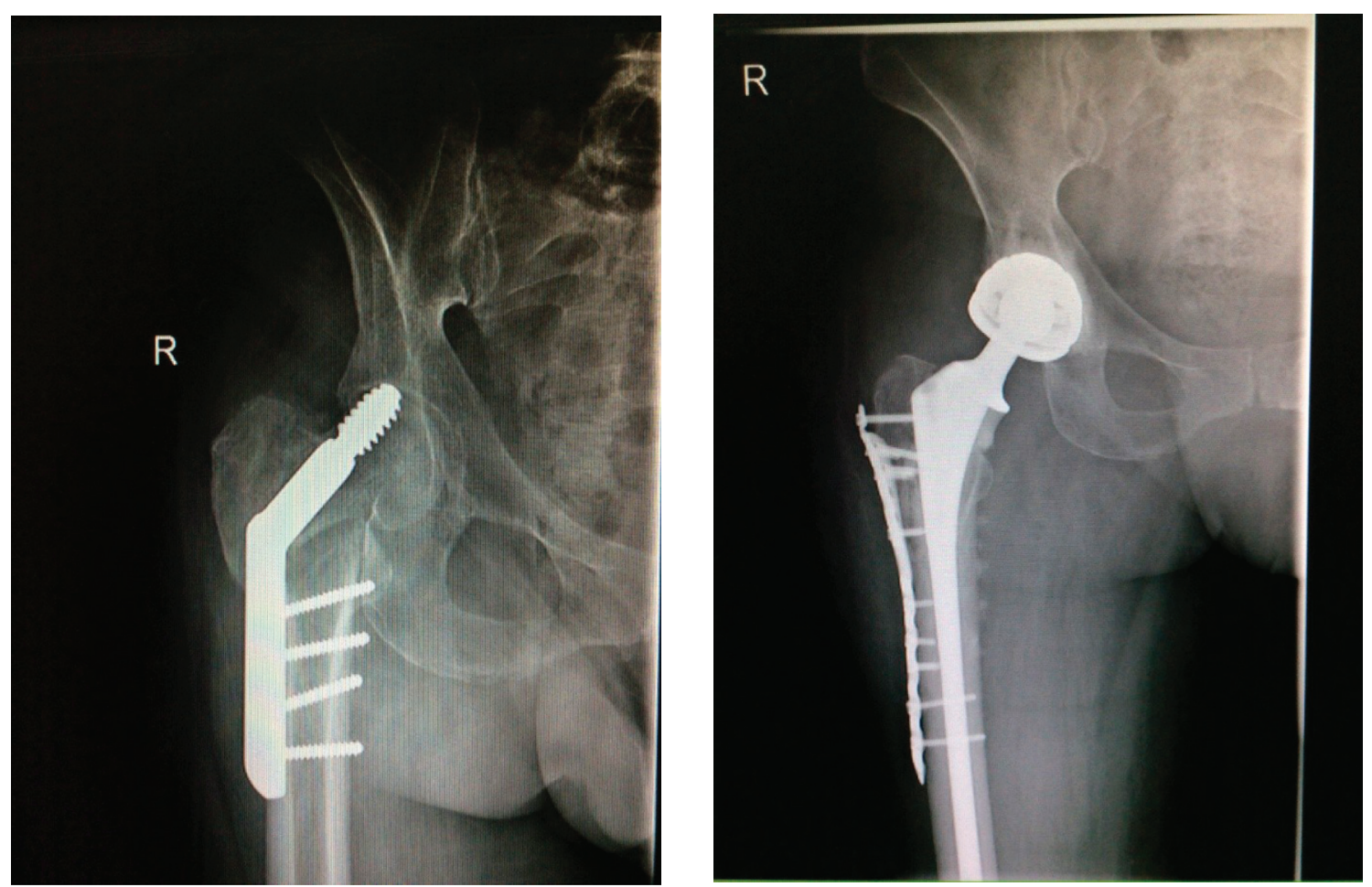

Figure 1. Radiograph of patient with failed DHS revised to dual mobility THR. Locking plate used to stabilize the trochanteric fracture.
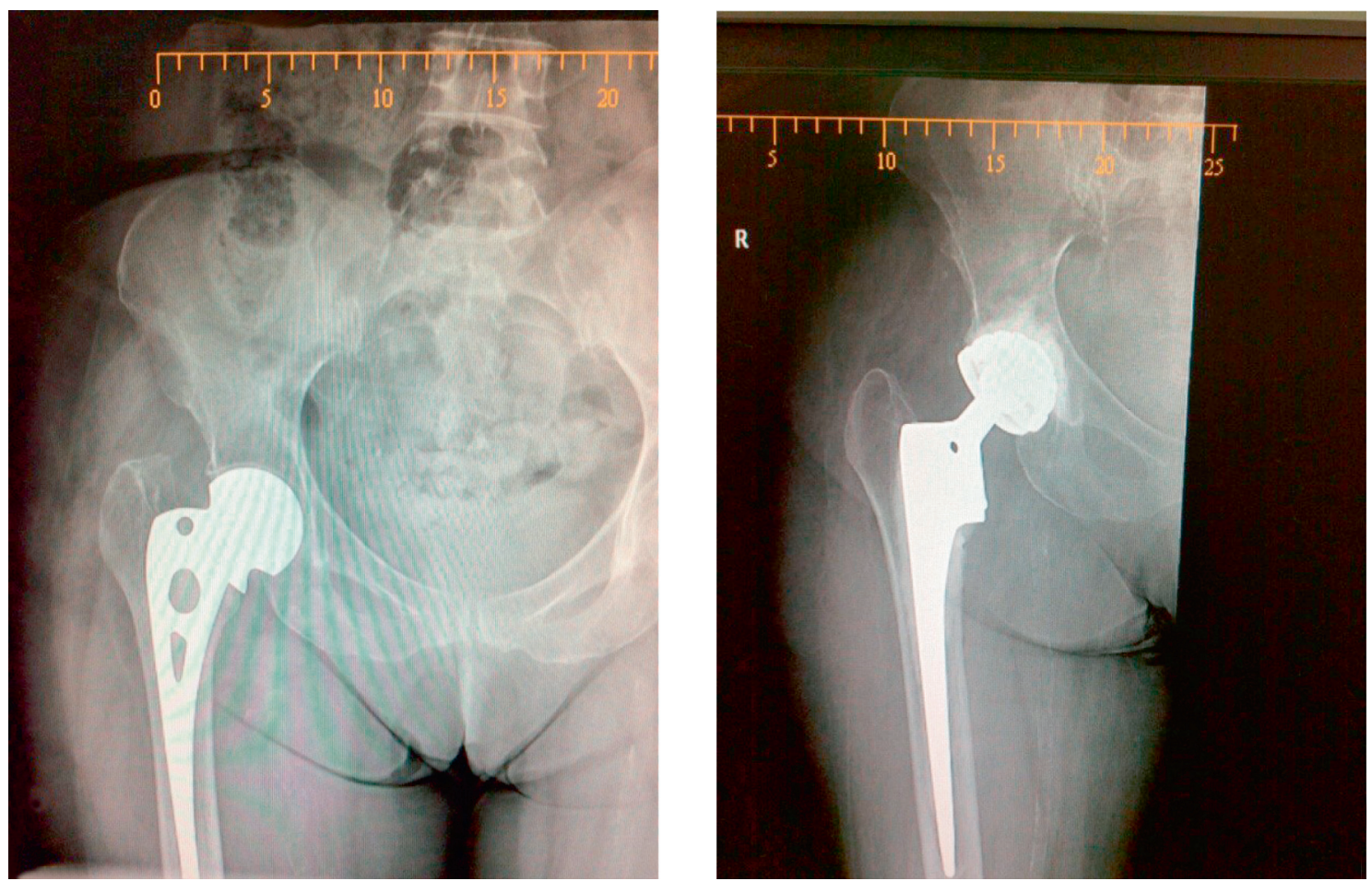

Figure 2. Failed Austin Moore prosthesis managed with calcar bearing dual mobility THR.

was the youngest patient, who had undergone attempted arthrodiastasis and his soft tissue envelope around the hip was compromised. Thirteen cases had undergone two or more previous surgeries. In one patient, the hip was operated seven times.
We used Clexane 4000 IU for postoperative deep vein thrombosis (DVT) prophylaxis routinely till the patients were mobilized. Aspirin was not considered a contraindication for surgery, but clopidogrel had to be stopped seven days before 
Table 1. Primary THR 30 cases.

\begin{tabular}{lc}
\hline Osteoarthritis & 17 \\
Femoral neck fracture & 9 \\
Fracture acetabulum & 3 \\
Sickle cell disease & 1 \\
\hline
\end{tabular}

Table 2. Revision surgery 35 cases.

\begin{tabular}{lc}
\hline Failed DHS & 11 \\
Failed hemiarthroplasty & 9 \\
Infection & 4 \\
Periprosthetic infection & 2 \\
Revision THR & 4 \\
Failed osteosynthesis & 5 \\
\hline
\end{tabular}

surgery. Patients on warfarin were taken up for surgery only after international normalized ratio (INR) was less than 1.5. The sickler patient underwent preoperative exchange transfusion to reduce his hemoglobin $\mathrm{S}(\mathrm{HbS})$ to $<40$. Drain was used routinely for $24-48 \mathrm{~h}$. The patients were mobilized postoperatively on day one after surgery with the help of a zimmer frame with weight bearing as tolerated.

The sutures were removed at two weeks after surgery. $\mathrm{X}$-rays were taken immediately postoperatively, one, three months, and one year after surgery. Ten patients agreed for a fluoroscopic evaluation after surgery (Figure 3).

\section{Results}

The follow-up of our cases has ranged from 18 months to six years with a mean follow-up of five years. There was a minor surgical wound related complication in six patients (three leaky wounds and three bruising under the skin), which settled after the stoppage of Clexane.

There was no dislocation seen in the primary total THR group. In one case of revision hip that was immunocompromised, tramadol addict with hepatocellular carcinoma, there was deep infection and dislocation. His infection could not be controlled despite antibiotics and debridement and he ended up with Girdlestone excision arthroplasty and eventually died due to his medical condition.

There was one mortality in the early postoperative period in an elderly patient who underwent an uncemented THR due to suspected myocardial infarction in the early postoperative period.

X-rays taken during follow-up have not shown any evidence of loosening around the acetabulum.

The fluoroscopic evaluation was done for 10 cases. In these cases, a mean flexion of $120^{\circ}$, abduction $30^{\circ}$, and adduction $10^{\circ}$ were observed (Figure 4 ). There was no impingement between the femoral neck and the metallic shell at extremes of movement. The third articulation between the polyethylene (PE) and the neck of femoral prosthesis could not be seen as the liner is radiolucent.

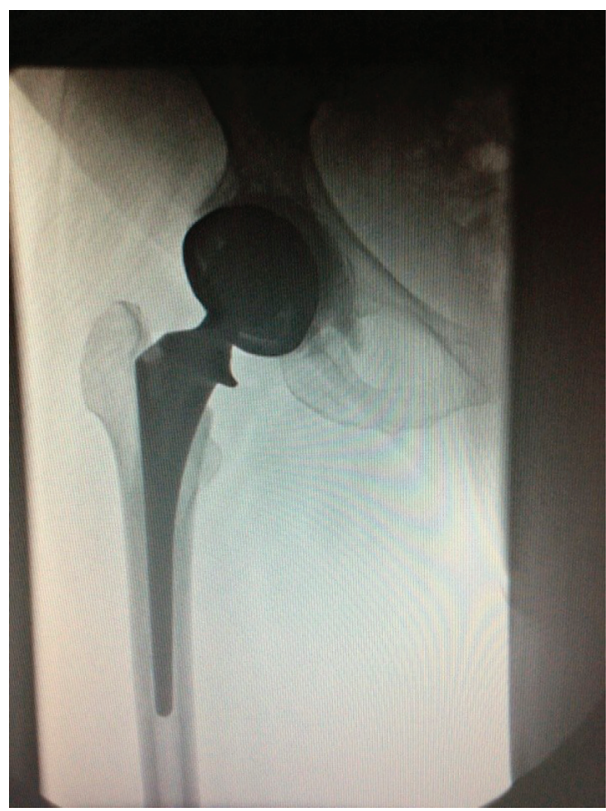

Figure 3. Fluoroscopic examination of a dual mobility THR.

Patients in our series would sit on the floor and pray as a custom in the local population, despite being advised not to do such activities.

\section{Discussion}

In our series, the DMC has been used for selective cases of hip replacement, which were at high risk of postoperative instability. The indication of DMC included patients who were either more than 60 years, were non compliant with a history of substance abuse, who had a history of prior hip surgery, had a compromised soft tissue envelope around the hip, and who were elderly and had sustained a femoral neck fracture. Our early results with these implants have shown a 98\% survivorship at a mean follow-up of five years without implant loosening. We have had no dislocations in our primary THR with DMC. Studies have shown a dislocation rate of $0-3.6 \%$ in primary THR $[6,7,9,26]$.

At 10 years the survivorship has ranged from 93 to $99 \%$ $[10,17]$, with one long-term study showing $80 \%$ survivorship at 22 years [7].

In the case of complex THR, the dislocation rate ranged from $5 \%$ to $30 \%$ because of the bone loss, compromised muscles, and soft tissues around the hips. The use of DMC in complex THR has shown the dislocation rate to range from $1 \%$ to $10 \%$ at eight year follow-up $[5,18,20,21,24,27]$. The implant survivorship has shown to be in the range of $95.6-96.2 \%$ at $3-8$ years $[5,18,20,27]$. We have used the DMC in 30 cases of complex THR and have had dislocation in one case.

The case of a septic hip undergoing THR had compromised soft tissues and has increased the chances of postoperative instability [28]. We have used such cups in four septic cases undergoing staged revision. The dislocation reported in our series has been shown in one such case. The patient had a 
(a)

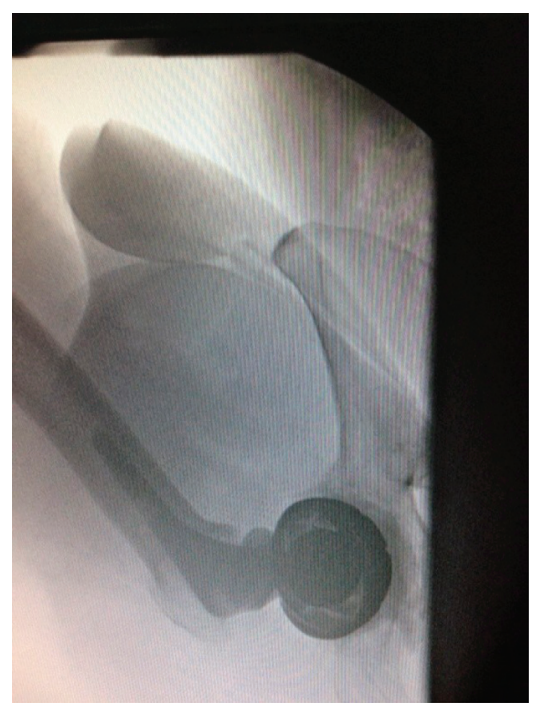

(b)

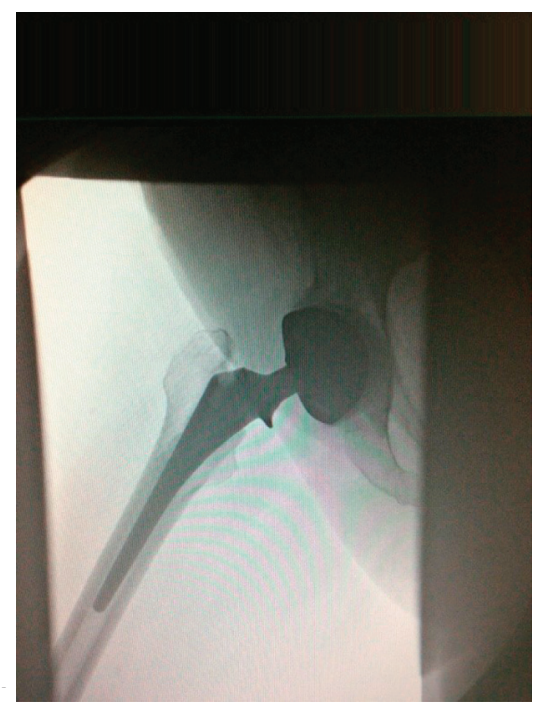

(c)

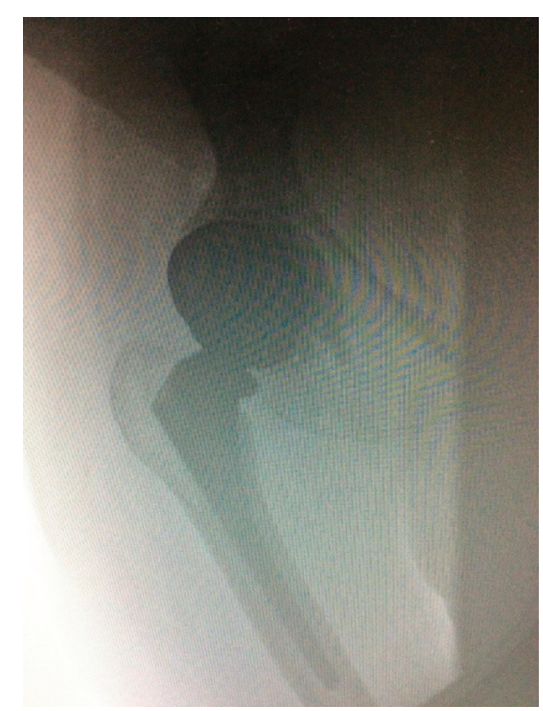

Figure 4. Fluoroscopic examination of a dual mobility THR in (a) flexion, (b) abduction and (c) adduction.

history of substance abuse and was immunocompromised with hepatocellular carcinoma and suffered from postoperative deep infection. He dislocated his hip and the periprosthetic infection could not be controlled with antibiotics and debridements and he ended up with Girdlestone excision arthroplasty.

Elderly patients with a femoral neck fracture have improved hip scores and better functional results after the THR [29]. There are higher postoperative dislocation rates following the THR after femoral neck fracture, which is almost five times higher than that reported for THR after osteoarthritis, meta-analysis has shown dislocation rates of $10.7 \%$ [30]. A randomized control trial comparing the internal fixation with THR in 100 patients found a dislocation rate of $22 \%$ in patients undergoing THR [29]. The use of DMC for THR in the case of a femoral neck fracture has shown a dislocation rate of $1.4 \%$ [31]. A comparison of dislocation rates has been done for conventional hip replacement and DMC replacement; there was a postoperative dislocation incidence of $14.3 \%$ in a conventional total hip and no dislocation was observed in the dual mobility group [32]. There were nine patients with femoral neck fracture, in our series five patients had failed osteosynthesis and four underwent THR primarily and no postoperative dislocation occurred. These patients sit on the floor and continue to pray on the floor as demanded by local customs.

Intraprosthetic dislocation (IPD) is peculiar to the DMC [33]. It occurs between the smaller head and polyliner due to a "bottle opener" effect. One has to be aware of the condition in order not to miss it which results in excessive metallosis and failure of the DMC [34]. The proposed theory causing IPD is the wear of PE retentive chamfer [7]. The head lies asymmetrically in the cup and might be mistaken for polywear. The dislocated liner has been described as a bubble sign and is pathognomic of intraprosthetic dislocation. The incidence of IPD in newer designs is probably lower because of polished neck and reduced wear of the liner at third articulation. In our mean follow-up of five years, we have not encountered this complication.
To the best of our knowledge, there has been no study in the literature evaluating these cups fluoroscopically. We have studied 10 cases fluoroscopically. There was no impingement between neck and metal cup at extremes of movement. It was difficult to comment on the articulation between the neck of the femoral prosthesis and the polyliner (third articulation) as it could not be seen due to the liner being radiolucent.

The addition of a radiopaque marker in the polyliner can help to evaluate movement at this articulation. The presence of this marker can also help in diagnosing IPD.

In younger patients, these cups should be used with caution as they are high demand cases and have high chances of PE wear and higher incidence of IPD [18, 27]. In our series, there were five patients under 40 years and the youngest was a sickler 23 years old who had arthrodiastasis done and had compromised soft tissue.

Ninety-six percent $(96 \%)$ of the dual mobility cups were cemented and no early radiographic loosening was seen at a mean follow-up of five years.

The limitation of our study that it is a retrospective study with a maximum follow-up of six years. The pre- and postoperative scoring with a validated hip scoring system which takes into account the lifestyle of our cohort of population, whose activities of daily living involve sitting on the floor not wearing shoes, would have helped in providing more information with functional results with these implant systems.

\section{Conclusion}

The DMC is an effective solution for the management of high risk cases undergoing total hip replacement for different causes to reduce the incidence of postoperative instability. The modification of a liner may be helpful to evaluate the system to diagnose the IPD. An alternate scoring system that takes into account different cultural aspects will help in the objective evaluation and comparison of results in different 
subsets of the population. A larger study group with a longer follow-up in randomized trials and meta-analysis are required to further confirm these findings.

\section{Conflict of interest}

The authors declare no conflict of interest in relation with this paper.

\section{References}

1. Patel PD, Potts A, Froimson MI (2007) The dislocating hip arthroplasty: prevention and treatment. J Arthroplasty 22, 86-90.

2. Berry DJ, von Knoch M, Schleck CD, Harmsen WS (2004) The cumulative long-term risk of dislocation after primary Charnley total hip arthroplasty. J Bone Joint Surg 86, 9-14.

3. Charnley J (1972) The long-term results of low-friction arthroplasty of the hip performed as a primary intervention. J Bone Joint Surg Br 54(1), 61-76.

4. Mckee GK, Watson-Farrar J (1966) Replacement of arthritic hips by the Mckee-Farrar prosthesis. J Bone Joint Surg Br 48(2), 245-259.

5. Philippot R, Adam P, Rechhaus M et al. (2009) Prevention of dislocation in total hip revision surgery using a dual mobility design. Orthop Traumatol Surg Res 95(6), 407-413.

6. Guyen O, Chen QS, Bejui-Hugnes J, Berry DJ, An KN (2007) Unconstrained tripolar hip implants: effect on hip stability. Clin Orthop Relat Res 455, 202-208.

7. Boyer B, Philippot R, Geringer J, Farizon F (2012) Primary total hip arthroplasty with dual mobility socket to prevent dislocation: a 22-year follow-up of 240 hips. Int Orthop 36(3), $511-518$

8. Hamadouche M, Amoukl H, Bouxin B (2012) Is a cementless dual mobility socket in primary THR a reasonable option? Clin Orthop Relat Res 470(11), 3048-3053.

9. Bouchet R, Mercier N, Saragaglia D (2011) Posterior approach and dislocation rate: a 213 total hip replacements case-control study comparing the dual mobility cup with a conventional 28-mm metal head/polyethylene prosthesis. Orthop Traumatol Surg Res 97(1), 2-7.

10. Combes A, Migaud H, Girard J, Duhamel A, Fessy MH (2013) Low rate of dislocation of dual mobility cups in primary total hip arthroplasty. Clin Orthop Relat Res 471(12), 3891-3900.

11. Philippot R, Farizon F, Camilleri JP et al. (2008) Survival of cementless dual mobility socket with a mean 17 years follow-up. Rev Chir Orthop Reparatrice Appar Mot 94(8), e23-e27.

12. Tarasevicius S, Robertsson O, Dobaz-inskas P, Wingstrand $\mathrm{H}$ (2013) A comparison of outcomes and dislocation rates using dual articulation cups and THA for intracapsular femoral neck fractures. Hip Int 23(1), 22-26.

13. Bensen AS, Jakobsen T, Krarup N (2014) Dual mobility cup reduces dislocation and re-operation when used to treat displaced femoral neck fractures. Int Orthop 1(18), 1-5.

14. Vielpeau C, Le bel B, Ardouin I, Burdin G, Lautridou G (2011) The dual mobility socket concept: experience with 668 cases. Int Orthop 35(2), 225-230.
15. Epinette JA, Beracassat R, Tracol P, Pagazani G, Vandenbussche F (2014) Are modern dual mobility cups a valuable option in reducing instability after primary hip arthroplasty even in younger patients? J Arthroplasty 29(6), 1323-1328.

16. Leclereq S, Benoit JY, de Rosa JP, Tallier E, Le teurtte C, Girardin PH (2013) Evora chromium-cobalt dual mobility socket: results at a minimum 10 years follow-up. Orthop Traumatol Surg Res 99(8), 923-928.

17. Prudhon JL, Ferreira A, Verdier R (2013) Dual mobility cup: dislocation rate and survivorship at ten years of follow-up. Int Orthop 37(12), 2345-2350.

18. Prudhon JL (2011) Dual-mobility cup and cemented femoral component: 6 year follow-up results. Hip Int 21(6), 713-717.

19. Leiber-Wackenbeim F, Brunsch-weikr B, Ehlinger M, Gabrion A, Mertl P (2011) Treatment of recurrent THR dislocation using of a cementless dual mobility cup: a 59 cases series with a mean 8 years follow-up. Orthop Traumatol Surg Res 97(1), 8-13.

20. Massin P, Besnier L (2010) Acetabular revision using a press fit dual mobility cup. Orthop Traumatal Surg Res 96(1), 9-13.

21. Hamadouche M, Biau DJ, Huten D, Musset T, Gauher F (2010) The use of a cemented dual mobility socket to treat recurrent dislocation. Clin Orthop Relat Res 468(12), 3248-3254.

22. Wegrzyn J, Pibarot V, Jacquel A, Carret JP, Bejui-Hugues J, Guyen O (2014) Acetabular reconstruction using a Kerboull cross-plate, structural allograft and cemented dual-mobility cup in revision THA at a minimum 5 year follow-up. J Arthroplasty 29(2), 432-437.

23. Langlais FL, Ropars M, Gaucher F, Musset T, Chaix O (2008) Dual mobility cemented cups have low dislocations rates in THA revisions. Clin Orthop Relat Res 466(2), 389-395.

24. Prudhon JL, Steffann F, Ferreira A, Verdier R, Aslanian T, Caton J (2014) Cementless dual-mobility cup in total hip arthroplasty revision. Int Orthop, 38(12), 2463-2468.

25. Mulholland SJ, Wyss UP (2001) Activities of daily living in non-Western cultures: range of motion requirements for hip and knee joint implants. Int J Rehabil Res 24, 191-198.

26. Farizon F, de Lavison R, Azoulai JJ, Bousquet G (1998) Results with a cementless alumina-coated cup with dual mobility. A twelve-year follow-up study. Int Orthop 22, 219-224.

27. Guyen O, Pibarot V, Vaz G, Chevillotte C, Béjui-Hugues J (2009) Use of a dual mobility socket to manage total hip arthroplasty instability. Clin Orthop Relat Res 467, 465-472.

28. Tabani S, Nagai Hajimi N, Kay P (2011) Old septic hip conversion to total hip replacement. J Bone Joint Surg Br, 93-B(SUPP II), 209.

29. Wang J, Jiang B, Marshall RJ, Zhang P (2009) Arthroplasty or internal fixation for displaced femoral neck fractures: which is the optimal alternative for elderly patients? A meta-analysis. Int Orthop 33, 1179-1187.

30. Iorio R, Healy WL, Lemos DW et al. (2001) Displaced femoral neck fractures in the elderly. Outcomes and cost-effectiveness. Clin Orthop 383, 229.

31. Adam P, Philippe R, Ehlinger M, Roche O, Bonnomet F, Molé D, Fessy MH (2012) Dual mobility cups hip arthroplasty as a treatment for displaced fracture of the femoral neck in the elderly. A prospective, systematic, multicenter study with 
specific focus on postoperative dislocation. Orthop Traumatol Surg Res 98, 296-300.

32. Tarasevicius S, Busevicius M, Robertsson $\mathrm{O}$, Wingstrand $\mathrm{H}$ (2010) Dual mobility cup reduces dislocation rate after arthroplasty for femoral neck fracture. BMC Musculoskelet Disord 11, 175 .
33. Marc S (2013) Concern about early intraprosthetic dislocation in dual-mobility implants. J Bone Joint Surg 3(3), e91-1.

34. Mohammed R, Cnudde P (2012) Severe metallosis owing to intraprosthetic dislocation in a failed dual-mobility cup primary total hip arthroplasty. J Arthroplasty 27(3), 493.e1-e3.

Cite this article as: Luthra JS, Al Riyami A \& Allami MK (2016) Dual mobility total hip replacement in a high risk population. SICOT J, 2, 43 